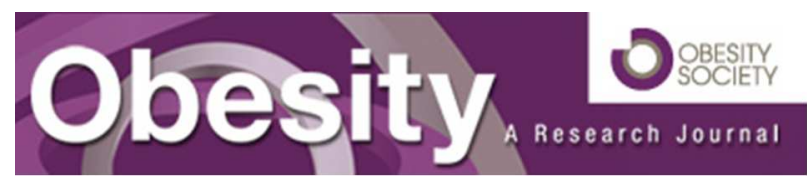

\title{
Association between trans fatty acid intake and overweight including obesity in 4-5-year-old children from the INMA study
}

\begin{tabular}{|c|c|}
\hline Journal: & Obesity \\
\hline Manuscript ID & 18-1005-Orig \\
\hline Manuscript Type: & Original Article \\
\hline Date Submitted by the Author: & 25-Sep-2018 \\
\hline Complete List of Authors: & $\begin{array}{l}\text { Scholz, Alexander; Universidad Miguel Hernandez de Elche - Campus San } \\
\text { Juan de Alicante, Unit of Nutritional Epidemiology } \\
\text { Navarrete-Muñoz, Eva Maria } \\
\text { Garcia de la Hera, Manuela; Universidad Miguel Hernandez, Salud Publica } \\
\text { Fernandez-Somoano, Ana ; CIBER de Epidemiología y Salud Pública } \\
\text { Tardón, Adonina; CIBER Epidemiología y Salud Pública (CIBERESP) } \\
\text { Santa-Marina, Loreto ; Public Health Department, Basque Government } \\
\text { Irazabal, Amaia ; Biodonostia Instituto de Investigacion Sanitaria } \\
\text { Romaguera, Dora } \\
\text { Guxens, Monica; ISGlobal, Centre for Research in Environmental } \\
\text { Epidemiology (CREAL) } \\
\text { Beneito, Andrea ; Universitat de València, Department of Statistics and } \\
\text { Computational Research } \\
\text { İñiguez, Carmen; FISABIO-Universitat Jaume I-Universitat de València, } 7 . \\
\text { Epidemiology and Environmental Health Joint Research Unit } \\
\text { Vioque, Jesus; Universidad Miguel Hernandez, Salud Pública; }\end{array}$ \\
\hline Keywords: & Childhood Obesity, Fatty Acids, Risk Factors \\
\hline
\end{tabular}




\title{
Association between trans fatty acid intake and overweight including obesity in 4-5-year-old children from the INMA study
}

\author{
Alexander Scholz ${ }^{1}$, Eva Maria Navarrete-Muñoz ${ }^{1,2}$, Manuela Garcia-de-la-Hera ${ }^{1,2}$, Ana \\ Fernandez-Somoano ${ }^{2,3}$, Adonina Tardon ${ }^{2,3}$, Loreto Santa Marina ${ }^{2,4,5}$, Amaia Irazabal ${ }^{4}$, Dora \\ Romaguera $^{6,7}$, Mònica Guxens ${ }^{2,8,9,10}$, Andrea Beneito ${ }^{11}$, Carmen Iñiguez ${ }^{11,12,2}$ \\ and Jesus Vioque ${ }^{1,2}$
}

${ }^{1}$ Unit of Nutritional Epidemiology, Miguel Hernandez University, Alicante 03550, Spain; scholz.alexander@gmail.com (A.S.); enavarrete@umh.es (E.M.N.-M.); manoli@umh.es (M.G.-d.-1.-H.); vioque@umh.es (J.V.)

${ }^{2}$ CIBER de Epidemiología y Salud Pública (CIBERESP), Madrid 28029, Spain; fernandezsana@uniovi.es (A.F.-S.); atardon@uniovi.es (A.T.); ambien4ss-san@euskadi.eus (L.S.M.); monica.guxens@isglobal.org (M.G.); beneito_and@gva.es (A.B.); inyiguez_car@gva.es (C.I.)

${ }^{3}$ Department of Medicine, University of Oviedo, Oviedo 33006, Spain

${ }^{4}$ BIODONOSTIA, Instituto de Investigación Biosanitaria, San Sebastián 20014, Spain; amaia-irazabal@hotmail.es

${ }^{5}$ Subdirección Salud Publica Gipuzkoa, San Sebastián 20013, Spain

${ }^{6}$ Instituto de Investigacion Sanitaria de Palma (IdISPa), Hospital Universitario Son Espases, Palma de Mallorca 07120, Spain; d.romaguera-bosch@imperial.ac.uk

${ }^{7}$ CIBER Fisiopatología de la Obesidad y Nutrición (CIBEROBN), Madrid 28029, Spain

${ }^{8}$ ISGlobal, Centre for Research in Environmental Epidemiology (CREAL), Barcelona 08036, Spain

${ }^{9}$ PompeuFabra University, Barcelona 08003, Spain 
${ }^{10}$ Department of Child and Adolescent Psychiatry/Psychology, Erasmus University Medical Centre-Sophia Children's Hospital, Rotterdam 3000CD, The Netherlands.

${ }^{11}$ Department of Statistics and Computational Research. Universitat de València, Valencia, Spain.

${ }^{12}$ Epidemiology and Environmental Health Joint Research Unit, FISABIO-Universitat Jaume I-Universitat de València, Valencia 46020, Spain

Key words: pediatric obesity, trans fatty acids, dietary fats, risk factors

Running title: Trans fatty acid intake and overweight in children

Corresponding author: Eva Maria Navarrete-Muñoz ${ }^{1}$; enavarrete@umh.es

Word count main text: 3385

Funding: Supported by Instituto Salud Carlos III (Red INMA G03/176 CB06/02/0041), Ministerio Sanidad y Fondos FEDER (FIS 03/1615; 04/1509; 04/1436; 05/1079; 06/1213; 06/0867; 07/0314; 11/01007; 13/1944; 14/00891), Conselleria Sanitat, Generalitat Valenciana (ACOMP/2010/115; 084/2010), Miguel Servet-FEDER (MS11/0178; MS15/0025)

Disclosure: The authors declared no conflict of interest 


\section{Study Importance Questions:}

\section{What is already known about this subject?}

- In adults, the intake of industrial, but not natural trans fatty acids has been associated with obesity.

- Little is known about the effect of the intake of different trans fatty acid subtypes on childhood obesity.

\section{What does our study add?}

- To our best knowledge, our study explores for the first time the association between the intake of industrial as well as natural trans fatty acids and overweight including obesity in preschool children. 


\begin{abstract}
(199 words)
\end{abstract}
Objective: The intake of trans fatty acids (TFA) has been associated with obesity in adults, although the evidence in children is scarce. We explored the association between total, industrial and natural TFA intake and overweight (including obesity) in 4-5-year-old Spanish children.

Methods: We cross-sectionally analyzed data of 1823 children aged 4-5 from the INMA study, a prospective mother-child cohort study in Spain. We estimated the intake of total, industrial and natural TFA in g/day using a validated food frequency questionnaire. Overweight including obesity was defined according to the International Obesity Task Force (IOFT) and World Health organization (WHO) criteria. We used multiple logistic regression to estimate adjusted odds ratios (OR) and confidence intervals $(95 \% \mathrm{CI})$.

Results: According to the IOTF criteria, the total TFA intake was associated with overweight (OR for one $\mathrm{g} / \mathrm{day}=1.57,95 \% \mathrm{CI} 1.02-2.40$ ). This association was stronger for industrial TFA intake $(\mathrm{OR}=1.87,95 \% \mathrm{CI} 1.07-3.25)$ whereas no association was observed for natural TFA intake ( $\mathrm{OR}=1.18,95 \% \mathrm{CI} 0.63-2.22)$. When the WHO criteria were used, no associations were observed.

Conclusions: Higher intake of total TFA, and particularly of industrial TFA, is associated with overweight in 4-5-year-old children when the IOTF criteria are used, but not when the WHO criteria are applied. 


\section{Introduction}

Childhood overweight (including obesity when not otherwise specified) has become a serious problem due to its increasing worldwide prevalence over the past decades with an important impact on individual and public health $(1,2)$. In high-income countries the prevalence of childhood overweight in 2013 was $23.8 \%$ in boys and $22.6 \%$ in girls (3). However, there is no general definition of childhood overweight. Widely used are the criteria proposed by the International Obesity Task Force (IOTF) which are based on age- and sex-specific BMI references corresponding to the cut-off points for overweight and obesity in adults (4). Other studies use the World Health Organization (WHO) criteria which are based on the BMI deviation from the WHO growth standard median (5). It has been reported that the IOTF criteria are more specific for identifying risk factors associated with overweight and that the WHO criteria are more sensitive (6).

Overweight in children is associated with overweight in adolescence as well as adulthood and an increased morbidity and mortality (7-9). Children with overweight are more likely to develop mostly preventable non-communicable diseases such as type 2 diabetes, cardiovascular diseases, musculoskeletal disorders and certain types of cancer (7).

Regarding the etiology of childhood overweight, numerous genetic and non-genetic risk factors have been identified $(7,9)$. However, a systematic review from 2013 that included 61 prospective studies concluded that the evidence was only strong for the association between childhood obesity and genetic factors as well as low physical activity. In contrast, the evidence was mixed for other factors such as sedentary lifestyle and dietary factors including sugar-sweetened beverage consumption and high fat intake (10). Moreover, the effect of total fat intake on bodyweight in children was recently analyzed in a Cochrane review and the results were inconclusive (11).

Nevertheless, studies in adults have shown that higher intake of specific fat types is associated with weight gain, particularly the intake of trans fatty acids (TFA) $(12,13)$. TFA are 
geometrical isomers of unsaturated fatty acids having at least one non-conjugated carboncarbon double bond in the trans configuration which can be of natural or industrial origin (14). Industrial TFA are artificially produced by partial hydrogenation of unsaturated vegetable oils during heating or deep fat frying, whereas natural TFA are present in meat or dairy products from ruminant animals where small amounts of TFA are produced by microorganisms in the rumen (15). There is growing evidence that the intake of TFA of natural or industrial origin may have different effects $(16,17)$. In adults, it is generally accepted that industrial TFA intake is associated with visceral adiposity and higher cardiovascular risk (18). In contrast, the intake of natural TFA has not been associated with changes in body size, shape or composition (19). However, the published literature about the association between TFA intake and childhood overweight is scarce and more studies are needed to investigate the role of TFA and its subtypes (20).

Therefore, we aimed to explore the association between the dietary intake of total, industrial and natural TFA and overweight in 4-5-year-old children in Spain. 


\section{Methods}

\section{Study design and participants}

The INMA project (INfancia y Medio Ambiente, Spanish for "Environment and Childhood") is a Spanish multicenter prospective population-based mother and child cohort study which consists of a network of birth cohorts with a common study protocol in the regions of Asturias, Gipuzkoa, Sabadell and Valencia. It aims to study the effects of diet and environmental factors during pregnancy and early childhood on child growth, development and health. The detailed study protocol was published elsewhere (21). Briefly, between November 2003 and August 2008 pregnant women were recruited and 2644 women agreed to participate. Finally, 2506 mothers and their newborns met the inclusion criteria and were included in the study. Of these children 1829 (73.0\%) were evaluated at the age of $4-5$ years between 2009 and 2012.

For the present analysis, we excluded six participants with missing data for some of the variables of interest. Thus, 1823 children $(99.7 \%)$ were finally included in the analysis. The mothers provided written informed consent and the study was approved by the Ethical Committees of the centers involved in the study (Hospital La Fe, Valencia; Hospital de Zumárraga, Gipuzkoa; CEIC-Parc de Salut Mar, Barcelona; Hospital Universitario Central de Asturias).

\section{Assessment of overweight and obesity}

When the children reached the age of 4-5 years, trained health professionals conducted personal interviews with the parents and took direct anthropometric measurements of the children's bodyweight and height following standardized protocols. Children's BMI was calculated by dividing weight in kilograms by square height in meters. Children were classified as overweight using the age- and sex-specific BMI cut-off points of the WHO criteria (z-score of $\mathrm{BMI} \geq 85^{\text {th }}$ percentile) as well as the cut-off points of the IOTF criteria 
$(22,23)$. To improve the readability, if not otherwise specified, we use throughout the paper the term overweight referring to children with overweight including obesity.

\section{Dietary Assessment including TFA}

A semi-quantitative food frequency questionnaire (FFQ) was used to assess the usual diet of the children previous to the interview (available at: http://epinut.edu.umh.es/cfa-105-inmainfancia/). Parents were asked to report how often, on average, their children had consumed the specified serving or portion size for each food item of the FFQ in the previous year. The questionnaire had nine possible responses, ranging from "never or less than once per month" to "six or more per day". The FFQ was derived from an adult version of the FFQ previously validated among the mothers participating in the INMA Study (24). The FFQ was modified to include foods and portion sizes appropriate to children aged 4-5 and further validated with three 24-hour recalls and several biomarkers in a sample of 169 children aged 4-5 from the Valencia cohort (25). The range of the reproducibility and validity coefficients of the FFQ were similar to those observed for other FFQs in the literature (26). Regarding the reproducibility and validity of the FFQ for the intake of TFA, the correlations were 0.44 and 0.23 , respectively; in both cases statistically significant (25).

Nutrient values were primarily obtained from food composition tables from the US Department of Agriculture (27), other published sources reporting information on TFA content in Spanish foods and other sources with detailed information for total, industrial and natural TFA in foods (27-32). We calculated the usual daily nutrient intakes for each child by multiplying the frequency of the use of each food item by the nutrient content of the portion size specified in the FFQ. Then we added all foods to obtain the total nutrient intake for each participant. The usual daily intake of TFA was expressed in g/day. Furthermore, we estimated the energy intake in kcals/day for each participant. We used the residual method to estimate 
calorie-adjusted values for the nutrient intakes (33). The usual daily fruit and vegetable intake as well as the sweetened beverage intake were estimated and expressed in $\mathrm{g} /$ day.

\section{Covariates}

The following parental variables were collected at baseline when pregnant women enrolled in the study or later at child birth: mother's educational level (none or primary, secondary, university), mother's social class (low, middle, high), pre-pregnancy mother's BMI (in $\mathrm{kg} / \mathrm{m}^{2}$ ), father's BMI (in $\mathrm{kg} / \mathrm{m}^{2}$ ) and smoking during pregnancy (no/yes). Additionally, the following variables of the children were collected and included: small for gestational age according to weight (no/yes), breastfeeding (no/yes), sex (male, female), age (in years), physical activity (low, middle, high) and TV viewing (in hours/day) as reported by parents at the age 4-5 years. Moreover, children with implausible calorie intake were identified by the formula of Goldberg et al. (34) with adapted cut-off points for European children aged 2 to 9 as proposed by Börnhorst et al. (35).

\section{Statistical analysis}

To compare the characteristics of the 4-5-year-old children with normal weight and those with overweight we performed univariate descriptive analyses. Analyses of variance (ANOVA) were applied for continuous variables and Chi-squared tests for categorical variables. Additionally, to explore the association between total, industrial, and natural TFA intake (in g/day) and overweight applying the IOTF and the WHO criteria, multiple logistic regression was used to estimate adjusted odds ratios (OR), 95\% confidence intervals (95\% CI) and $\mathrm{p}$ values. Moreover, a further analysis was done with total, industrial and natural TFA intake expressed in quartiles. Two different models were performed for all analyses: a basal model (Model 1) adjusted for sex, age, total energy intake and study cohort and a second model (Model 2) additionally adjusted for major risk factors of childhood obesity (mother's 
educational level, mother's social class, mother's BMI, father's BMI, physical activity, TV viewing, fruit and vegetable intake and soft drink intake). We observed no heterogeneity between the four study cohorts $\left(\mathrm{I}^{2}=0-3 \%\right)$. Thus, the four cohorts were combined, and the regression models were adjusted for the variable study cohort. Furthermore, a sensitivity analysis was performed by excluding from the analysis children with implausible calorie intake ( $n=64$ ), overweight children ( $n=267$ for the IOTF criteria, $n=170$ for the WHO criteria) and including in the adjusted Model 2 the variables small for gestational age according to weight, breast feeding or smoking during pregnancy.

All statistical analyses were conducted with the statistical software $\mathrm{R}$, version 3.2.3 (R Foundation for Statistical Computing, Vienna, Austria). All statistical tests were bilateral and p-values $<0.05$ were considered statistically significant. 


\section{Results}

Table 1 shows the characteristics of the parents and children $(n=1823)$ according to the children's weight status. The prevalence of overweight was $20.5 \%$ when applying the IOTF criteria and $31.5 \%$ when using the WHO criteria. Significant differences between children with overweight and children with normal weight were observed for both criteria. The prevalence of overweight in parents of children with overweight was higher than in children with normal weight with a higher difference for the mothers than for the fathers. The percentage of children viewing TV more than 1 hour per day was about 10 points higher in children with overweight than in children with normal weight for both criteria. Moreover, when applying the IOFT criteria, we observed a higher intake of industrial TFA in children with overweight. When using the WHO criteria, we found a significantly higher fruit and vegetable intake in children with overweight when compared to children with normal weight. Table 2 shows the results of the logistic regression analysis that reveals the association between total, natural as well as industrial TFA intake (in g/day) and overweight in children. When we applied the IOTF criteria, the intake of total TFA was statistically significant associated with overweight in Model 2 which was adjusted for major risk factors of childhood overweight (OR 1.57, 95\% CI 1.02; 2.40). A stronger positive association was observed between the intake of industrial TFA and overweight in the basal Model 1 (OR 1.96, 95\% CI 1.17 ; 3.27) and in Model 2 (OR 1.87, 95\% CI 1.07; 3.25). We observed no statistically significant association between the intake of natural TFA and overweight. For the WHO criteria the tendencies of the associations were similar, but the associations were weaker (OR for industrial TFA in both models 1.36) and did not reach statistical significance.

As shown in table 3, for the IOTF criteria and after adjusting for major risk factors, when comparing the highest with the lowest quartile, the OR of the association between total TFA intake and overweight was 1.40 (95\% CI $0.99 ; 2.00, \mathrm{p}$ for trend 0.032$)$. When comparing the highest quartile with the lowest quartile of industrial TFA intake, a statistically significant 
association with overweight was found (OR $1.58,95 \%$ CI $1.12 ; 2.24$, p for trend of 0.012 ). No statistically significant associations were observed between the quartiles of natural TFA intake and overweight. Again, for the WHO criteria the tendencies of the associations were similar but weaker and did not reach statistical significance.

Figure 1 shows a sensitivity analysis of the association between industrial TFA intake and overweight vs. normal weight applying the IOTF and the WHO criteria. No major changes were observed when excluding children with implausible calorie intake or when Model 2 was additionally adjusted for the variables small for gestational age according to weight, breastfeeding or smoking during pregnancy. When excluding the overweight children, the confidence interval widened and no statistically significant association between industrial TFA intake and obesity was observed. 


\section{Discussion}

To our knowledge, we addressed for the first time the association between the intake of different TFA subtypes and childhood overweight. In 4-5-year-old Spanish children total and to a greater extend industrial TFA intake was significantly associated with overweight when applying the IOTF criteria. This association was weaker and did not reach statistical significance when applying the WHO criteria. No statistically significant association was found between natural TFA intake and overweight for both criteria.

The existence of different childhood overweight criteria complicates the interpretation and comparison of data on its prevalence and associated factors. In previous studies the different criteria have been compared and it has been shown that the IOTF criteria are more specific and the WHO criteria more sensitive $(6,36,37)$. Therefore, it has been suggested that in future studies the results of both criteria should be presented to improve the comparability (38). In our study, the prevalence of overweight was $20.5 \%$ when applying the IOTF criteria and $31.5 \%$ when applying the WHO criteria, which is consistent with a higher specificity of the IOTF criteria and higher sensitivity of the WHO criteria. However, this difference underlines the importance of defining universal criteria in the future. Meanwhile we should be aware of the characteristics of the different criteria and interpret study results according to them.

There are no large epidemiological studies published that analyze the association between TFA intake and childhood overweight which limits the comparison of our results. We found a positive association between total TFA intake and overweight when applying the more specific IOTF criteria. These results are in line with two large long-term prospective observational studies in adults that have shown the association between TFA intake and weight gain $(39,40)$. However, at the present moment the biological mechanisms by which TFA could contribute to overweight remain unclear (13). Interestingly, in our study the association between overweight and TFA was stronger for industrial TFA and no significant 
association was observed for natural TFA. Therefore, as total TFA intake is the sum of natural and industrial TFA intake it could be assumed that the observed associations are based on the effect of industrial TFA. To confirm these findings, we adjusted in an additional analysis the industrial TFA intake for natural TFA intake and vice versa and the results did not change (not shown). This observation is in accordance to recent findings that suggest that industrial and natural TFA could have different effects on a variety of health outcomes. On the one hand, industrial TFA intake has been associated with insulin resistance, coronary heart disease and sudden death (18) as well as increased visceral adiposity and bodyweight (41). On the other hand, natural TFA intake has not been associated with coronary heart disease which has initially been explained by the relatively low natural TFA intake by adults (42). However, recent studies revealed that higher plasma concentrations of natural TFA have been associated with lower triacylglycerol concentration, lower blood pressure and a lower type 2 diabetes risk (16). Furthermore, in a prospective cohort study with 267 Danish participants aged 3565, natural TFA intake was not significantly associated with changes in bodyweight, waist and hip circumference or body fat percentage (19). Thus, our results are consistent with the findings about the different metabolic effects of the TFA subtypes in adults but should be confirmed in prospective studies. Moreover, other health outcomes than overweight should be addressed in future studies with children.

When analyzing the association between quartiles of TFA intake and overweight applying the IOTF criteria it could be observed that the association was strongest for the highest quartile of TFA intake when compared to the lowest quartile. For total TFA intake, the association was marginally not statistically significant when adjusting for major risk factors. However, a statistically significant trend was observed which indicated a stronger association for higher total TFA intake. For industrial TFA intake, a clear association was observed for the highest quartile compared to the lowest quartile. Again, no significant associations were found for natural TFA. These findings suggest that the intake of mainly industrial TFA was associated 
with overweight in a dose dependent manner. The WHO recommends that total TFA intake should be less than one percent of the total energy intake, but no limits are expressed for industrial TFA intake in particular (43). Although lately many measures have been undertaken to diminish the industrial TFA content of foods (18), our findings and the previously mentioned evidence for different effects of industrial and natural TFA suggest that the recommendations should be actualized and a specific threshold for industrial TFA intake should be established.

When applying the WHO criteria, a weak, not statistically significant association between total TFA intake and overweight was observed. Although this association was slightly stronger for industrial TFA it did not reach statistical significance. These findings may be explained by the lower specificity of the WHO criteria. As stated earlier, in our study $31.5 \%$ of the participants were classified as having overweight or obesity by the WHO criteria. This corresponds to nearly one third of the study population. It is to be expected that the lower threshold for overweight in our study population makes it less probable to obtain statistically significant differences between the groups. However, it could also be argued that the association between total and especially industrial TFA intake and overweight is not strong enough to be detected by less specific obesity criteria, but this assumption could lead to a serious underestimation of the health risks of TFA intake. While the application of less specific criteria can be a disadvantage when associations between obesity and risk factors are tested because more children are falsely classified as having obesity (false-positives), in clinical practice it could be preferable to use less specific but more sensitive criteria to minimize the number of children with obesity not detected (false-negatives) (6). Therefore, it is crucial to know the characteristics of the different childhood obesity criteria to obtain in each situation the maximal benefit for the children.

In the sensitivity analysis no substantial changes were observed when we additionally adjusted for the variables small for gestational age according to weight, breastfeeding or 
smoking during pregnancy. However, there is limited evidence that these variables could interfere with childhood overweight (10). Likewise, no significant differences were observed when excluding children with implausible calorie intake. When we excluded children with overweight and compared children with normal weight only to children with obesity, signification was lost for the IOTF criteria. This could be explained by the relatively low number of obese children in our study which diminished the statistical power of this analysis. The present study has several limitations. The cross-sectional analysis of the data at 4-5 years of age does not permit causal inference, which means that it cannot be assumed that the higher TFA intake causes the higher prevalence of childhood overweight. However, overweight at the age of 4-5 year should be recent, and most of the variables were collected several years before at baseline when the mother and child cohort study started. In addition, to our knowledge we describe this association for the first time in this population distinguishing the different TFA subtypes. This permits us to generate a hypothesis, but our results should be confirmed in prospective studies to rule out reverse causation or other bias. Moreover, despite adjusting for multiple variables in the regression models we cannot rule out a potential residual confounding by other variables that we did not address. Another limitation is the existence of different childhood overweight criteria which can, as we show, lead to different results. Therefore, it is crucial to know and consider the differences in sensitivity and specificity between the criteria when interpreting and comparing study results.

\section{Conclusion}

Higher intake of total and, to a greater extend, industrial TFA, was positively associated with overweight including obesity when applying the more specific IOTF criteria for childhood obesity. No negative effect was observed for natural TFA. Our results should be confirmed in prospective studies. Meanwhile, TFA and particularly industrial TFA should be restricted from the diet of children. 


\section{References}

1. Lobstein T, Jackson-Leach R, Moodie ML, et al. Child and adolescent obesity: part of a bigger picture. Lancet Lond Engl 2015;385:2510-2520.

2. Abarca-Gómez L, Abdeen ZA, Hamid ZA, et al. Worldwide trends in body-mass index, underweight, overweight, and obesity from 1975 to 2016: a pooled analysis of 2416 population-based measurement studies in 128.9 million children, adolescents, and adults. The Lancet 2017;390:2627-2642.

3. Ng M, Fleming T, Robinson M, et al. Global, regional, and national prevalence of overweight and obesity in children and adults during 1980-2013: a systematic analysis for the Global Burden of Disease Study 2013. Lancet Lond Engl 2014;384:766-781.

4. Lobstein T, Baur L, Uauy R, IASO International Obesity TaskForce. Obesity in children and young people: a crisis in public health. Obes Rev Off J Int Assoc Study Obes 2004;5 Suppl $1: 4-104$.

5. de Onis M, Onyango AW, Borghi E, Siyam A, Nishida C, Siekmann J. Development of a WHO growth reference for school-aged children and adolescents. Bull World Health Organ $2007 ; 85: 660-667$.

6. Valerio G, Balsamo A, Baroni MG, et al. Childhood obesity classification systems and cardiometabolic risk factors: a comparison of the Italian, World Health Organization and International Obesity Task Force references. Ital J Pediatr 2017;43:19.

7. Han JC, Lawlor DA, Kimm SY. Childhood obesity. The Lancet 2010;375:1737-1748.

8. Bjørge T, Engeland A, Tverdal A, Smith GD. Body mass index in adolescence in relation to cause-specific mortality: a follow-up of 230,000 Norwegian adolescents. Am J Epidemiol $2008 ; 168: 30-37$. 
9. Lakshman R, Elks CE, Ong KK. Childhood obesity. Circulation 2012;126:1770-1779.

10. Pate RR, O’Neill JR, Liese AD, et al. Factors associated with development of excessive fatness in children and adolescents: a review of prospective studies. Obes Rev Off J Int Assoc Study Obes 2013;14:645-658.

11. Naude CE, Visser ME, Nguyen KA, Durao S, Schoonees A. Effects of total fat intake on bodyweight in children. In: The Cochrane Library. John Wiley \& Sons, Ltd, 2018.

12. Mozaffarian D, Aro A, Willett WC. Health effects of trans-fatty acids: experimental and observational evidence. Eur J Clin Nutr 2009;63 Suppl 2:S5-21.

13. Thompson AK, Minihane A-M, Williams CM. Trans fatty acids and weight gain. Int J Obes $20052011 ; 35: 315-324$.

14. Nishida C, Uauy R. WHO Scientific Update on health consequences of trans fatty acids: introduction. Eur J Clin Nutr 2009;63:S1-S4.

15. Bhardwaj S, Passi SJ, Misra A. Overview of trans fatty acids: biochemistry and health effects. Diabetes Metab Syndr 2011;5:161-164.

16. Da Silva MS, Julien P, Pérusse L, Vohl M-C, Rudkowska I. Natural Rumen-Derived trans Fatty Acids Are Associated with Metabolic Markers of Cardiac Health. Lipids 2015;50:873882.

17. Smit LA, Willett WC, Campos H. trans-fatty acid isomers in adipose tissue have divergent associations with adiposity in humans. Lipids 2010;45:693-700.

18. Mozaffarian D. Dietary and Policy Priorities for Cardiovascular Disease, Diabetes, and Obesity: A Comprehensive Review. Circulation 2016;133:187-225. 
19. Hansen CP, Heitmann BL, Sørensen TI, Overvad K, Jakobsen MU. Intake of ruminant transfatty acids, assessed by diet history interview, and changes in measured body size, shape and composition. Public Health Nutr 2016;19:494-502.

20. Innis SM. Trans fatty intakes during pregnancy, infancy and early childhood. Atheroscler Suppl 2006;7:17-20.

21. Guxens M, Ballester F, Espada M, et al. Cohort Profile: the INMA--INfancia y Medio Ambiente--(Environment and Childhood) Project. Int J Epidemiol 2012;41:930-940.

22. Anon. (2015). WHO | WHO Child Growth Standards: Methods and development. [WWW document]. URL http://www.who.int/childgrowth/standards/technical_report/en/

23. Cole TJ, Bellizzi MC, Flegal KM, Dietz WH. Establishing a standard definition for child overweight and obesity worldwide: international survey. BMJ 2000;320:1240.

24. Vioque J, Navarrete-Muñoz E-M, Gimenez-Monzó D, et al. Reproducibility and validity of a food frequency questionnaire among pregnant women in a Mediterranean area. Nutr $J$ $2013 ; 12: 26$

25. Vioque J, Gimenez-Monzo D, Navarrete-Muñoz EM, et al. Reproducibility and Validity of a Food Frequency Questionnaire Designed to Assess Diet in Children Aged 4-5 Years. PloS One 2016;11:e0167338.

26. Ortiz-Andrellucchi A, Henríquez-Sánchez P, Sánchez-Villegas A, Peña-Quintana L, Mendez M, Serra-Majem L. Dietary assessment methods for micronutrient intake in infants, children and adolescents: a systematic review. Br J Nutr 2009;102 Suppl 1:S87-117.

27. Anon. U.S. Department of Agriculture: Agricultural Research Service, USDA National Nutrient Database for Standard Reference, Release 27. 
28. Leth T, Ovesen L, Hansen K. Fatty acid composition of meat from ruminants, with special emphasis on trans fatty acids. J Am Oil Chem Soc 1998;75:1001-1005.

29. Larqué E, Garaulet M, Pérez-Llamas F, Zamora S, Tebar FJ. Fatty acid composition and nutritional relevance of most widely consumed margarines in Spain. Grasas Aceites 2003;54.

30. Vicario IM, Griguol V, León-Camacho M. Multivariate characterization of the fatty acid profile of spanish cookies and bakery products. J Agric Food Chem 2003;51:134-139.

31. Fernández-San Juan P-M. Trans fatty acids (tFA): sources and intake levels, biological effects and content in commercial Spanish food. Nutr Hosp 2009;24:515-520.

32. Kuhnt K, Baehr M, Rohrer C, Jahreis G. Trans fatty acid isomers and the trans-9/trans-11 index in fat containing foods. Eur J Lipid Sci Technol EJLST 2011;113:1281-1292.

33. Willett W. Nutritional Epidemiology. Oxford University Press; 2013.

34. Goldberg GR, Black AE, Jebb SA, et al. Critical evaluation of energy intake data using fundamental principles of energy physiology: 1. Derivation of cut-off limits to identify underrecording. Eur J Clin Nutr 1991;45:569-581.

35. Börnhorst C, Huybrechts I, Ahrens W, et al. Prevalence and determinants of misreporting among European children in proxy-reported 24 h dietary recalls. Br J Nutr 2013;109:12571265.

36. Lobstein T. Commentary: which child obesity definitions predict health risk? Ital J Pediatr 2017;43:20.

37. Pelegrini A, Silva DAS, Gaya ACA, Petroski EL. Comparison of three criteria for overweight and obesity classification in brazilian adolescents. Nutr $J$ 2013;12:5. 
38. de Onis M, Lobstein T. Defining obesity risk status in the general childhood population: which cut-offs should we use? Int J Pediatr Obes IJPO Off J Int Assoc Study Obes $2010 ; 5: 458-460$.

39. Koh-Banerjee P, Chu N-F, Spiegelman D, et al. Prospective study of the association of changes in dietary intake, physical activity, alcohol consumption, and smoking with 9-y gain in waist circumference among 16587 US men. Am J Clin Nutr 2003;78:719-727.

40. Field AE, Willett WC, Lissner L, Colditz GA. Dietary fat and weight gain among women in the Nurses' Health Study. Obes Silver Spring Md 2007;15:967-976.

41. Micha R, Mozaffarian D. Trans fatty acids: effects on metabolic syndrome, heart disease and diabetes. Nat Rev Endocrinol 2009;5:335-344.

42. Bendsen NT, Christensen R, Bartels EM, Astrup A. Consumption of industrial and ruminant trans fatty acids and risk of coronary heart disease: a systematic review and meta-analysis of cohort studies. Eur J Clin Nutr 2011;65:773-783.

43. Anon. (2018). WHO | Fats and fatty acids in human nutrition. [WWW document]. URL http://www.who.int/nutrition/publications/nutrientrequirements/fatsandfattyacids_humannutrit ion/en/ 
Table 1: Characteristics of the parents and 4-5-year-old children participating in the INMA study according to the children's weight status

\begin{tabular}{|c|c|c|c|c|c|c|}
\hline & \multicolumn{3}{|c|}{ International Obesity Task Force criteria } & \multicolumn{3}{|c|}{ World Health Organization criteria } \\
\hline & $\begin{array}{l}\text { Normal } \\
\text { weight, } \\
n=1449\end{array}$ & $\begin{array}{c}\text { Overweight } \\
\text { including } \\
\text { obesity, } \\
\mathrm{n}=374\end{array}$ & $\mathrm{p}^{\mathrm{a}}$ & $\begin{array}{l}\text { Normal } \\
\text { weight, } \\
\mathrm{n}=1249\end{array}$ & $\begin{array}{l}\text { Overweight } \\
\text { including } \\
\text { obesity, } \\
n=574\end{array}$ & $\mathrm{p}^{\mathrm{a}}$ \\
\hline Maternal education (university), $\%$ & 38.2 & 33.4 & 0.117 & 37.6 & 36.4 & 0.574 \\
\hline Maternal social class (low), $\%$ & 24.8 & 21.1 & 0.092 & 24.9 & 22.1 & 0.196 \\
\hline Maternal BMI ( $\geq 25), \%$ & 22.5 & 40.4 & $<0.001$ & 21.7 & 36.0 & $<0.001$ \\
\hline Paternal BMI ( $\geq 25), \%$ & 53.5 & 68.8 & $<0.001$ & 52.3 & 65.9 & $<0.001$ \\
\hline \multicolumn{7}{|l|}{ Child characteristics } \\
\hline Sex (females), $\%$ & 47.3 & 52.7 & 0.062 & 49.2 & 46.5 & 0.280 \\
\hline Age, y, mean (SD) & $4.41(0.18)$ & $4.43(0.21)$ & 0.061 & $4.41(0.19)$ & $4.42(0.19)$ & 0.156 \\
\hline Physical activity (high), \% & 16.0 & 12.7 & 0.117 & 16.1 & 13.5 & 0.253 \\
\hline TV viewing, h/day $(>1), \%$ & 58.0 & 66.7 & 0.009 & 57.7 & 64.5 & 0.020 \\
\hline Fruit and vegetable intake, g/day, mean (SD) & $216(121)$ & $228(129)$ & 0.096 & $215(122)$ & $228(124)$ & 0.030 \\
\hline Soft drink intake, g/day, mean (SD) & $81(107)$ & $88(130)$ & 0.281 & $82(106)$ & $84(125)$ & 0.703 \\
\hline Total calorie intake/day, mean (SD) & $1577(346)$ & $1598(370)$ & 0.301 & $1582(349)$ & $1580(354)$ & 0.924 \\
\hline Total TFA intake, g/day, mean (SD) & $1.31(0.30)$ & $1.35(0.29)$ & 0.052 & $1.32(0.30)$ & $1.33(0.30)$ & 0.458 \\
\hline Industrial TFA intake, g/day, mean (SD) & $0.58(0.22)$ & $0.61(0.22)$ & 0.025 & $0.58(0.22)$ & $0.59(0.22)$ & 0.447 \\
\hline Natural TFA intake, g/day, mean (SD) & $0.69(0.20)$ & $0.69(0.19)$ & 0.636 & $0.69(0.20)$ & $0.69(0.20)$ & 0.715 \\
\hline
\end{tabular}

${ }^{a}$ p-values from the chi-squared tests for categorical variables and ANOVA tests for continuous variables 
Table 2: Association between total, industrial as well as natural TFA intake and overweight including obesity in 4-5-year-old children from the INMA study

\begin{tabular}{|c|c|c|c|c|c|c|c|c|}
\hline & \multicolumn{4}{|c|}{ International Obesity Task Force criteria } & \multicolumn{4}{|c|}{ World Health Organization criteria } \\
\hline & \multirow{2}{*}{$\begin{array}{c}\text { Normal weight, } \\
n=1449\end{array}$} & \multicolumn{3}{|c|}{$\begin{array}{l}\begin{array}{l}\text { Overweight including obesity, } \\
\mathrm{n}=374\end{array}\end{array}$} & \multirow{2}{*}{$\begin{array}{l}\text { Normal weight, } \\
n=1249\end{array}$} & \multicolumn{3}{|c|}{$\begin{array}{l}\text { Overweight including obesity, } \\
\mathrm{n}=574\end{array}$} \\
\hline & & $\mathrm{OR}^{\mathrm{a}}$ & $95 \% \mathrm{CI}$ & $\mathrm{p}$ & & $\mathrm{OR}^{\mathrm{a}}$ & $95 \% \mathrm{CI}$ & $\mathrm{p}$ \\
\hline \multicolumn{9}{|c|}{ Total TFA, g/day } \\
\hline Model $1^{\mathrm{b}}$ & 1.00 & 1.43 & $0.97 ; 2.10$ & 0.068 & 1.00 & 1.17 & $0.83 ; 1.63$ & 0.376 \\
\hline Model $2^{c}$ & 1.00 & 1.57 & $1.02 ; 2.40$ & 0.039 & 1.00 & 1.30 & $0.89 ; 1.88$ & 0.174 \\
\hline \multicolumn{9}{|c|}{ Industrial TFA, g/day } \\
\hline Model $1^{\mathrm{b}}$ & 1.00 & 1.96 & $1.17 ; 3.27$ & 0.011 & 1.00 & 1.36 & $0.86 ; 2.15$ & 0.189 \\
\hline Model $2^{c}$ & 1.00 & 1.87 & $1.07 ; 3.25$ & 0.027 & 1.00 & 1.36 & $0.83 ; 2.22$ & 0.226 \\
\hline \multicolumn{9}{|c|}{ Natural TFA, g/day } \\
\hline Model $1^{b}$ & 1.00 & 0.97 & $0.54 ; 1.73$ & 0.907 & 1.00 & 0.96 & $0.58 ; 1.59$ & 0.870 \\
\hline Model $2^{c}$ & 1.00 & 1.18 & $0.63 ; 2.22$ & 0.600 & 1.00 & 1.19 & $0.69 ; 2.05$ & 0.541 \\
\hline
\end{tabular}

${ }^{\mathrm{a}} \mathrm{OR}$ was obtained by logistic regression

${ }^{\mathrm{b}}$ Adjusted for sex, age, total energy intake, study cohort

${ }^{\mathrm{c}}$ Model 1 additionally adjusted for mother's educational level, mother's social class, mother's BMI, father's BMI, physical activity, TV viewing, fruit and vegetable intake, soft drink intake 
Table 3: Association between quartiles of total, industrial as well as natural TFA intake and overweight including obesity in 4-5-year-old children from the INMA study

\begin{tabular}{|c|c|c|c|c|c|c|}
\hline \multirow[b]{3}{*}{ Quartiles of TFA intake } & \multicolumn{3}{|c|}{$\begin{array}{c}\text { International Obesity Task Force } \\
\text { criteria }\end{array}$} & \multicolumn{3}{|c|}{ World Health Organization criteria } \\
\hline & \multicolumn{3}{|c|}{$\begin{array}{l}\text { Overweight including obesity, } \\
\qquad \mathrm{n}=374\end{array}$} & \multicolumn{3}{|c|}{$\begin{array}{l}\text { Overweight including obesity, } \\
\qquad \mathrm{n}=574\end{array}$} \\
\hline & $\mathrm{OR}^{\mathrm{a}}$ & $95 \% \mathrm{CI}$ & $\mathrm{p}$ & $\mathrm{OR}^{\mathrm{a}}$ & $95 \% \mathrm{CI}$ & $\mathrm{p}$ \\
\hline \multicolumn{7}{|l|}{ Total TFA, g/day } \\
\hline $\mathrm{Q} 1(<1.11)$ & 1.00 & (reference) & & 1.00 & (reference) & \\
\hline Q2 (1.11-1.29) & 0.89 & $0.62 ; 1.26$ & 0.501 & 0.85 & $0.63 ; 1.14$ & 0.276 \\
\hline Q3 (1.30-1.49) & 1.07 & $0.75 ; 1.52$ & 0.702 & 1.03 & $0.77 ; 1.39$ & 0.828 \\
\hline $\mathrm{Q} 4(\geq 1.50)$ & 1.40 & $0.99 ; 2.00$ & 0.061 & 1.13 & $0.83 ; 1.53$ & 0.445 \\
\hline $\mathrm{p}$ for trend & & & 0.032 & & & 0.263 \\
\hline \multicolumn{7}{|l|}{ Industrial TFA, g/day } \\
\hline Q1 $(<0.44)$ & 1.00 & (reference) & & 1.00 & (reference) & \\
\hline Q2 (0.44-0.54) & 1.08 & $0.76 ; 1.53$ & 0.665 & 1.00 & $0.74 ; 1.33$ & 0.976 \\
\hline Q3 (0.55-0.69) & 1.11 & $0.78 ; 1.58$ & 0.555 & 0.93 & $0.69 ; 1.25$ & 0.624 \\
\hline $\mathrm{Q} 4(\geq 0.70)$ & 1.58 & $1.12 ; 2.24$ & 0.010 & 1.18 & $0.87 ; 1.60$ & 0.277 \\
\hline $\mathrm{p}$ for trend & & & 0.012 & & & 0.377 \\
\hline \multicolumn{7}{|l|}{ Natural TFA, g/day } \\
\hline Q1 $(<0.55)$ & 1.00 & (reference) & & 1.00 & (reference) & \\
\hline Q2 (0.55-0.67) & 1.20 & $0.86 ; 1.70$ & 0.286 & 1.10 & $0.82 ; 1.48$ & 0.525 \\
\hline Q3 (0.68-0.80) & 1.27 & $0.90 ; 1.80$ & 0.171 & 1.25 & $0.93 ; 1.68$ & 0.147 \\
\hline Q4 $(\geq 0.81)$ & 1.04 & $0.72 ; 1.49$ & 0.843 & 0.96 & $0.70 ; 1.31$ & 0.786 \\
\hline $\mathrm{p}$ for trend & & & 0.784 & & & 0.997 \\
\hline
\end{tabular}

${ }^{\mathrm{a}}$ OR was obtained by logistic regression applying Model 2 (adjusted for sex, age, total energy intake, study cohort, mother's educational level, mother's social class, mother's BMI, father's BMI, physical activity, TV viewing, fruit and vegetable intake, soft drink intake) 
Figure 1: Sensitivity analysis of the association between industrial TFA intake and overweight/obesity vs. normal weight applying the IOTF and the WHO criteria. All shown models except for Model 1 are based on Model 2. 
Figure 1: Sensitivity analysis of the association between industrial TFA intake and overweight/obesity vs. normal weight applying the IOTF and the WHO criteria. All shown models except for Model 1 are based on Model 2. 